\title{
Barriers of Consumer Behavior for the Development of the Circular Economy in Russia
}

\author{
Svetlana Ratner ${ }^{1,2}$, Konstantin Gomonov ${ }^{1, *}$ \\ ${ }^{1}$ Peoples' Friendship University of Russia (RUDN University), Economic Faculty, Department of economic and \\ mathematical modelling, Moscow, Russia \\ ${ }^{2}$ V. A. Trapeznikov Institute of Control Sciences, Russian Academy of Sciences, Moscow, Russia \\ ${ }^{*}$ Corresponding author. Email: gomonov-kg@rudn.ru
}

\begin{abstract}
In this paper, we study the barriers of the circular economy associated with the change in patterns of consumer behavior. The method of the study is a face-to-face survey on a questionnaire aimed at determining the reasons why consumers practice (or do not practice) each of the 57 patterns of pro-environmental behavior (PEBs). The research methodology is based on a literature review of European and Asian experiences and previous research on changing consumer behavior patterns. Field research through a questionnaire aimed to determine why consumers practice or not practice each of the practices. The questionnaire contained, among other things, questions aimed at clarifying the environmental literacy and environmental self-awareness of the respondents. The survey involved students from Russian universities whose educational programs include environmental management courses, environmental safety, etc. This choice of respondents is explained by the fact that this category of consumers is the most informed and most flexible in forming a pro-ecological consumer behavior pattern. The processing of the survey results carried out using nonparametric statistics due to the absence of a normal distribution of the sample for most of the studied characteristics. The results showed that environmental competence is influenced by external and internal factors that need to be coordinated in environmental education.
\end{abstract}

Keywords: Consumer behavior, Circular economy, Environmental literacy, Survey.

\section{INRODUCTION}

The concept of circular economy (CE) opens up new radical changes in the consumption patterns and lifestyles of people. In CE the global production system should be designed in such way that all useful resources taken from the environment could be repeatedly reused and the waste from one production chain could be the starting material for building another. In contrast to the linear model of modern economy "extract-produce-use-dump", which stimulates the consumer to constantly change consumer goods and replacing them with newer ones, in economy of the circular type, it is important to extend the product life cycle as long as possible by the following cycles: 1 ) reuse; 2) remanufacturing: 3) recycling; 4) disposal [1]. It's important that the more the product is in the first cycles, the cheaper it is, in general, to manufacture it compared to the situation when the product goes to recycling immediately after use (traditional linear model of the production system).
The transition to the concept of $\mathrm{CE}$ requires not only the restructuring of production chains but also the reformatting of many logistic, informational and managerial relationships, as well as a change in consumer behavior patterns [2,3]. Consumer readiness for such a cardinal change in traditional patterns should be formed gradually with the transition from simple practices of resource-saving and waste management to more complex ones.

The research objective of this paper is to assess the willingness of the Russian population to change towards a more environmentally friendly daily practice of consuming energy and water, waste management, city mobility and choosing goods when shopping. To achieve the research aims, we used a face-to-face questionnaire survey of a pilot consumer group. To achieve this goal, the authors of the study try to determine which practices are the most popular, which practices are most consistent, how the popularity of practices depends on the level of income, how the popularity of practices depends on 
gender, how does the popularity of practices depend on the level of environmental responsibility.

\section{LITERATURE REVIEW}

The promotion of pro-environmental behavior in people's daily lives is one of the key issues in the development of the circular economy, in addition to the efforts of the industrial and commercial sectors. Therefore, this issue has been studied quite well in modern scientific literature. As evidenced by numerous studies, an awareness of the environmental problems and ecology concerns are characteristic of almost all stratums of society, regardless of gender, age, type of activity, etc. [4-6]. However, the same is not true for the environmental activity of people, their ability to abandon their usual consumer behavior, and take the path of "greening" everyday household practices [7-9]. That is, even if people are well aware of environmental issues, there are many internal and external barriers to taking real steps to prevent harmful consumer behavior or reduce its negative impact and consequences [10]. These barriers can be driven by various factors, such as traditional values, lifestyles, politics, infrastructure, and surroundings circumstances, and can vary widely across cultures and countries [3, 11].

One of the most common methods for studying barriers to consumer pro-environmental behavior (PEB) is different types of questionnaire surveys [12]. Despite the fact that this method has its significant drawbacks which are also actively discussed in the literature [13,14], it remains a priority tool in conducting primary research with the goal to obtain a general picture of the popularity of one particular model of consumer behavior and identify the reasons of unpopularity of another.

\section{METHODOLOGY}

To study the real and potential barriers to proenvironmental consumer behavior patterns, we conducted a face-to-face survey of 100 respondents with the questionnaire, which was developed based on the results of a comparative analysis of similar studies conducted in other countries. The questionnaire consisted of three parts. The first part of the questionnaire was informational and fixed the socio-demographic data of the respondent.

The questions of the second part of the questionnaire were aimed at determining the respondents' attitudes to environmental responsibility issues (general level of environmental self-awareness). The respondent was asked to answer the question of whether they believe that they can improve the environment in their city and indicate the types of environmental measures in which they took part at least once. The questions of the third part of the questionnaire were aimed at assessing the frequency and reasons for applying (or not applying) practices of pro-environmental behavior in the field of energy conservation, water conservation, waste management, reducing the use of disposable products and mobility. The questionnaire also contained questions aimed at clarifying the respondents' environmental literacy and environmental self-awareness. The respondents were students of Russian universities, whose educational programs include courses on environmental management, environmental safety, etc. This choice of respondents is explained by the fact that this category of consumers is the most informed and most flexible in terms of forming pro-environmental patterns of consumer behavior.

In compiling a list of pro-environmental behaviors, we used a variation of the questionnaire, proposed by [15]. This work was chosen for the following reasons: firstly, it contains the widest list of possible practices of pro-environmental behavior (includes 58 practices); secondly, it has already been used by other scientists as a basis for international comparisons [11], which allows us to further (when conducting a larger study) compare the results obtained for Russia with the results of other countries. It should be noted that from the entire list of 58 practices of pro-environmental behavior, some are almost unknown in modern Russian society; nevertheless, they were included in the study in order to identify possible patterns of behavior transmitted from generation to generation as a way of lean housekeeping. Several practices were excluded from the list due to the inability to use in Russia, a contradiction to cultural or legal norms. Instead, several new energy-saving practices have been added. In general, our set of PEBs is $90 \%$ similar to the set of [15].

Selected 57 patterns in our study were divided into 6 groups: 1) patterns in the field of energy conservation; 2) patterns in the field of water conservation; 3) patterns in the field of waste management; 4) patterns that can be arbitrarily called "against plastic" (reducing the use of disposable tableware, packaging, etc.); 5) shopping patterns; 6) urban mobility patterns. This division is explained by the fact that some groups of patterns (for example, in the field of energy efficiency) have been actively promoting at the state level for more than 10 years, while others (for example, deciding in favor of purchasing more environmentally friendly goods) have not yet been stimulated. The list of patterns, divided into groups, are presented in tab. 1.When answering the question of how often respondents' practice each of the 57 models of pro-environmental behavior, one could choose the answer options "never", "rarely", "often" or "always", which, when processed, were translated into a scale from 1 to 4 . Besides, respondents were also asked to choose the reasons for the application or non-use of these practices. Among the possible reasons for applying the practice were "Habit", "Laziness", "Money saving", "Sense of duty", "Fashion", and among the reasons for non-use - "Laziness", "Time consuming", "No 
Table 1. Pro-environmental patterns of consumers' behavior

\begin{tabular}{|c|c|}
\hline Group of PEBs & Description of PEBs \\
\hline Energy saving & $\begin{array}{l}\text { P1 Avoiding overloading the refrigerator, P2 Reducing opening and closing the door } \\
\text { of the refrigerator, P3 Using a lower setting in the refrigerator compartment, P4 Putting } \\
\text { hot food into the refrigerator after cooling, P5 Using stairs instead of elevators, P6 } \\
\text { Cleaning filter of the air conditioner or cleaner, P7 Adjusting the temperature of the air } \\
\text { conditioner, P8 Turning off lights in empty rooms, P9 Unplugging appliances not in } \\
\text { use, P10 Turning off the TV when people are not watching, P11 Using energy-saving } \\
\text { mode or turning off when not in use, P12 Doing ironing collectively, P13 Setting a } \\
\text { lower shower temperature, P14 Adjusting the temperature of the radiator, P29 } \\
\text { Avoiding over-volume cooking, P30 Water heating of the required volume in an } \\
\text { electric kettle, P31 Covering the pan with a lid when cooking or boiling water, P40 } \\
\text { Buying energy efficient appliances, P54 Using LED lamp instead of a fluorescent } \\
\text { lamp, P56 Flame adjustment for cooking, P57 Use of residual heat when cooking on } \\
\text { an electric stove }\end{array}$ \\
\hline Water saving & $\begin{array}{l}\text { P15 Using toothbrush cup, P16 Turning off the water when washing face or brushing } \\
\text { teeth, P17 Taking short showers, P18 Washing dishes using jugged water,P19 } \\
\text { Reducing detergent, P20 Cutting down on the frequency of washing clothes,P55 } \\
\text { Using dishwasher }\end{array}$ \\
\hline Waste management & $\begin{array}{l}\text { P21 Avoiding throwing away waste cooking oil, P22 Following garbage rules, P23 } \\
\text { Garbage separation, P24 Giving used clothes to other people or using a recycle box, } \\
\text { P25 Collection and delivery of glass containers to appropriate collection points, P26 } \\
\text { Waste paper collection and delivery to appropriate collection points, P27 Collection } \\
\text { and delivery of used batteries, light bulbs to appropriate collection points, P32 } \\
\text { Composting kitchen garbage, P33 Throwing away kitchen garbage after it has dried, } \\
\text { P46 Using both sides of the paper }\end{array}$ \\
\hline No plastic & $\begin{array}{l}\text { P28 Using own cup, P34 Using receptacle instead of plastic bag, P35 Using own bag } \\
\text { when going shopping, P36 Reducing use of disposable products, P37 Not buying } \\
\text { over-packaged products }\end{array}$ \\
\hline Shopping & $\begin{array}{l}\text { P38 Buying organic products, P39 Buying recycled goods, P41 Buying ecomark- } \\
\text { appliances, P42 Choosing goods with their CO2 emission in mind (carbon footprint), } \\
\text { P43 Not buying unnecessary products, P44 Trying to repair things before buying } \\
\text { replacements, P45 Using refill goods }\end{array}$ \\
\hline Mobility & $\begin{array}{l}\text { P47 Using bicycle or walking, P48 Using public transportation, P49 Joining the one } \\
\text { day without car program, P50 Doing car checks regularly, P51 Avoiding overloading } \\
\text { the car, P52 Reducing idling of the car, P53 Maintaining air pressure of the tire }\end{array}$ \\
\hline
\end{tabular}

Source: compiled by the authors.

consideration", "Forget", "Nobody doing", "Cost", "There are no conditions for application", "I did not know that it was so necessary." The choice of each of the reasons was encoded as a Boolean variable ( 0 or 1$)$.

Further, the investigation for answers to research questions was carried out using descriptive and nonparametric statistics. The use of nonparametric statistics is explained by the fact that the studied variables are not distributed normally and are measured on an ordinal scale. Research questions and methods of verification are given in table 2 .

\section{RESULTS AND DISCUSSION}

The most popular PEBs were P4 "Putting hot food into refrigerator after cooling", P8 "Turning off lights in empty rooms", P10 "Turning off the TV when people are not watching", P11 "Using energy saving mode or turning off when not in use", P12“Doing ironing

Table 2. Research questions and methods

\begin{tabular}{|l|l|}
\hline \multicolumn{1}{|c|}{ Research questions } & Method of study \\
\hline $\begin{array}{l}\text { Q1: What are the most popular / unpopular PEBs (in general and in a } \\
\text { group) }\end{array}$ & Descriptive statistics \\
\hline Q2: Which groups of PEBs are the most popular / unpopular & Descriptive statistics \\
\hline Q3: The most coherent and discordant PEBs & Descriptive statistics \\
\hline Q4: How the popularity of PEBs depends on income & Kruskall-Wallis Test \\
\hline Q5: How popularity of PEBs depends on gender & Mann-Whitney Test \\
\hline $\begin{array}{l}\text { Q6: How popularity of PEBs depends on the level of environmental } \\
\text { responsibility (theoretical, real) }\end{array}$ & Mann-Whitney Test \\
\hline Q7: What are the most common reasons for not practicing PEBs? & Descriptive statistics \\
\hline
\end{tabular}


collectively", P56" Flame adjustment for cooking "and P28“ Using own cup". They have a median equal 4 . The least popular PEBs with a median equal 1 were P15 "Using toothbrush cup", P18 "Washing dishes using jugged water", P21 "Avoiding throwing away waste cooking oil", P23 “Garbage separation", P25 “Collection and delivery of glass containers to appropriate collection points ", P26 "Waste paper collection and delivery to appropriate collection points ", P27 "Collection and delivery of used batteries, light bulbs to appropriate collection points ", P32 "Composting kitchen garbage", P33 "Throwing away kitchen garbage after it has dried", P34 "Using receptacle instead of plastic bag", P42 "Choosing goods with their CO2 emission in mind (carbon footprint)", P49 "Joining the one day without car program ".

The most consistent PEBs are P56 "Flame adjustment for cooking", P10 "Turning off the TV when people are not watching", P18 "Washing dishes using jugged water", P8 "Turning off lights in empty rooms", P25 "Collection and delivery of glass containers to appropriate collection points", and P15 "Using toothbrush cup "(standard deviation less than 0.6). The largest scatter of scores is observed for PEBs P57 "Use of residual heat when cooking on an electric stove", P16 "Turning off the water when washing face or brushing teeth", P51 "Avoiding overloading the car", P53 "Maintaining air pressure of tire" .

Among the groups of practices, the most popular were PEBs on energy conservation (median 3, mean 2.8), the least popular practices on waste management (median 1 , mean 1.75) (Fig. 1).

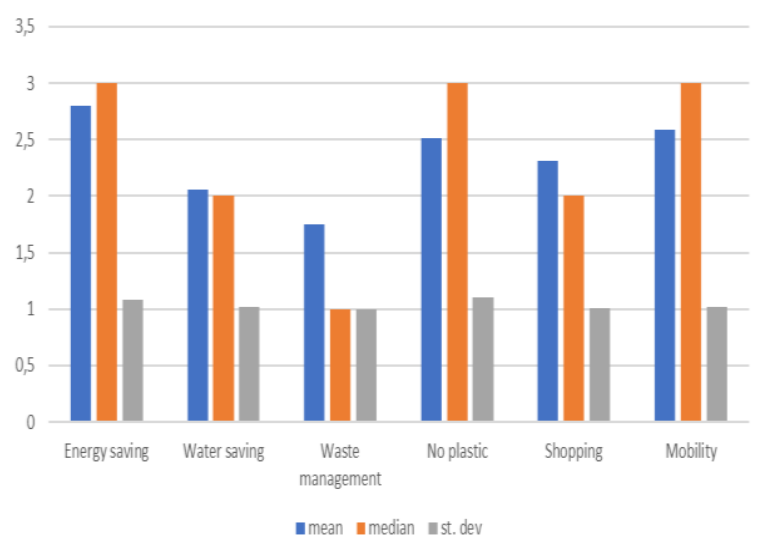

Figure 1 Groups of PEBs popularity. Source: compiled by the authors.

The most often chosen reason for not applying proenvironmental practices for household waste management was the answer "No necessary conditions for use," which suggests that the vast majority of respondents for almost all practices listed in the questionnaire could make them at least more often used in the presence of appropriate collection points for glass containers, waste paper, old clothes, used batteries and light bulbs.

However, the popular answers about the reasons for non-use were "I don't see the need", "laziness", "wasting time", "forgetting", which indicates an insufficient level of environmental self-awareness even in one of the group of respondents who is most informed and flexible in everyday skills.

Statistically significant differences in the popularity of practices on the "gender" variable were identified only for practices P4 "Putting hot food into refrigerator after cooling", P50 "Doing car checks regularly", P21 "Avoiding throwing away waste cooking oil", P22 "Following garbage rules", P33 "Throwing away kitchen garbage after it has dried", P35 "Using own bag when going shopping", P37 "Not buying over-packaged products", P47 "Using bicycle or walking" and P49 "Joining the one day without car program". All these PEBs are practiced more often by men than by women.

Further, using the Mann-Whitney test, we tested the hypothesis that the level of environmental responsibility affects the frequency of use of pro-environmental behavior models. The "Responsibility" variable was coded as 1 if the respondent believed that he could improve the environment in his city and as 0 if he did not consider it possible or had no definite opinion on this issue. Statistically significant differences in the popularity of PEBs for the "Responsibility" variable were identified only for PEBs P13 "Setting a lower shower temperature", P38 "Buying organic products", P49 "Joining the one day without car program" and P50 "Doing car checks regularly" (tab. 3). As expected, respondents that are more responsible are more likely to practice these behaviors than others.

The degree of environmental involvement was also encoded by a Boolean variable. If the respondent participated at least once in any type of environmental protection measures (including donations), then his answer was encoded as 1 , otherwise - 0 . Statistically significant differences in the popularity of practices in the "Responsibility" variable were identified only for PEBs P11 "Using energy saving mode or turning off when not in use", P13 "Setting a lower shower temperature", P24 "Giving used clothes to other people or using a recycle box", P26 "Waste paper collection and delivery to appropriate collection points" and P45 "Using refill goods" (tab. 3). As expected, respondents who are more involved in environmental activities more often practice these behaviors than inactive respondents. 
Table 3. Results of the non-parametric Mann-Whitney Test

\begin{tabular}{|c|c|c|c|}
\hline \begin{tabular}{|ll} 
Independent & (grouping) \\
variable
\end{tabular} & Depended PEBs & Z-statistics & Comparisons \\
\hline \multirow[t]{9}{*}{ Gender } & P4 & $-1.76^{\star}$ & $M>F$ \\
\hline & P50 & $1.69^{\star}$ & $\mathrm{M}>\mathrm{F}$ \\
\hline & P21 & $1.88^{\star}$ & $\mathrm{M}>\mathrm{F}$ \\
\hline & P22 & $1.97^{\star \star}$ & $\mathrm{M}>\mathrm{F}$ \\
\hline & P33 & $3.76^{\star * *}$ & $M>F$ \\
\hline & P35 & $1.88^{*}$ & $\mathrm{M}>\mathrm{F}$ \\
\hline & P37 & $1.95^{\star}$ & $\mathrm{M}>\mathrm{F}$ \\
\hline & P47 & $2.21^{\star \star}$ & $\mathrm{M}>\mathrm{F}$ \\
\hline & P49 & $2.56^{\star \star}$ & $\mathrm{M}>\mathrm{F}$ \\
\hline \multirow[t]{4}{*}{ Responsibility } & P13 & $2.25^{\star \star}$ & $1>0$ \\
\hline & P38 & $1.84^{*}$ & $1>0$ \\
\hline & P49 & $1.89^{*}$ & $1>0$ \\
\hline & P50 & $1.69^{*}$ & $1>0$ \\
\hline \multirow[t]{5}{*}{ Participation } & $\mathrm{P} 11$ & $1.92^{*}$ & $1>0$ \\
\hline & $\mathrm{P} 13$ & $2.75^{\star \star \star}$ & $1>0$ \\
\hline & P24 & $2.50^{\star *}$ & $1>0$ \\
\hline & P26 & $2.51^{\star *}$ & $1>0$ \\
\hline & $\mathrm{P} 45$ & $2.47^{\star \star}$ & $1>0$ \\
\hline
\end{tabular}

Source: compiled by the authors. Note: $\mathrm{p}=0,1 *, \mathrm{p}=0,05 * *, \mathrm{p}=0,01^{* * *}$

Statistically significant differences in the frequency of use of the proposed models of pro-ecological behavior depending on income level were identified by practices P1 "Avoiding overloading the refrigerator", P12 "Doing ironing collectively", P30 "Water heating of the required volume in an electric kettle", P16 "Turning off the water when washing face or brushing teeth", P50 "Doing car checks regularly", P23 "Garbage separation", P39 "Buying recycled goods" (tab. 4).

\section{Table 4. Results of non-parametric Kruskall-Wallis} Test

\begin{tabular}{|c|c|c|}
\hline $\begin{array}{c}\text { Independent } \\
\text { (grouping) variable }\end{array}$ & $\begin{array}{c}\text { Depend } \\
\text { ed PEBs }\end{array}$ & H-statistics \\
\hline \multirow{4}{*}{ Income } & P1 & $7.57^{*}$ \\
\cline { 2 - 3 } & P12 & $8.83^{\star *}$ \\
\cline { 2 - 3 } & P30 & $7.67^{*}$ \\
\cline { 2 - 3 } & P16 & $6.96^{*}$ \\
\cline { 2 - 3 } & P50 & $7.3^{*}$ \\
\cline { 2 - 3 } & P23 & $7.32^{*}$ \\
\hline
\end{tabular}

Source: compiled by the authors. Note: $\mathrm{p}=0,1^{*}, \mathrm{p}=0,05$ $* *, \mathrm{p}=0,01 * * *$

However, a more detailed study of the revealed differences with "Box \& Whiskers" Plots, does not allow interpret them meaningfully. So, for example, people with middle incomes (group code - 3) are more likely to avoid overloading the refrigerator, people with high incomes (group code - 4) do this less often, and people with low incomes (group code - 2) never do this (fig. 2a). Most often, people who work with collective ironing are low-income people, people with an average income are less likely to do it, and people with a high income quite often practice this model (fig. $2 b$ ).

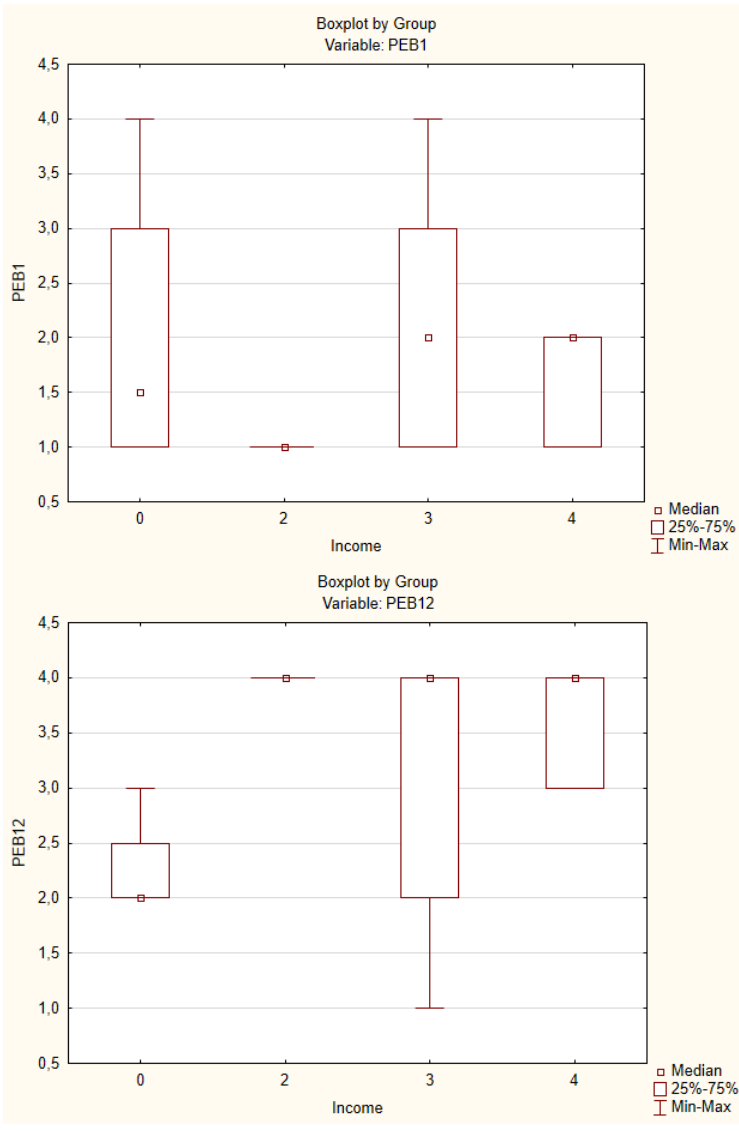

Figure 2 "Box \& Whiskers" Plots for P1 and P12.

People with a high level of income most often practice a limited amount of water heating in a teapot; on the contrary, low-income respondents almost never use this energy-saving practice (fig. 3a). Water saving by turning it off while brushing ones teeth is practiced most often by people with an average income; low-income respondents hardly practice such a behavior model (fig. $3 b)$. 


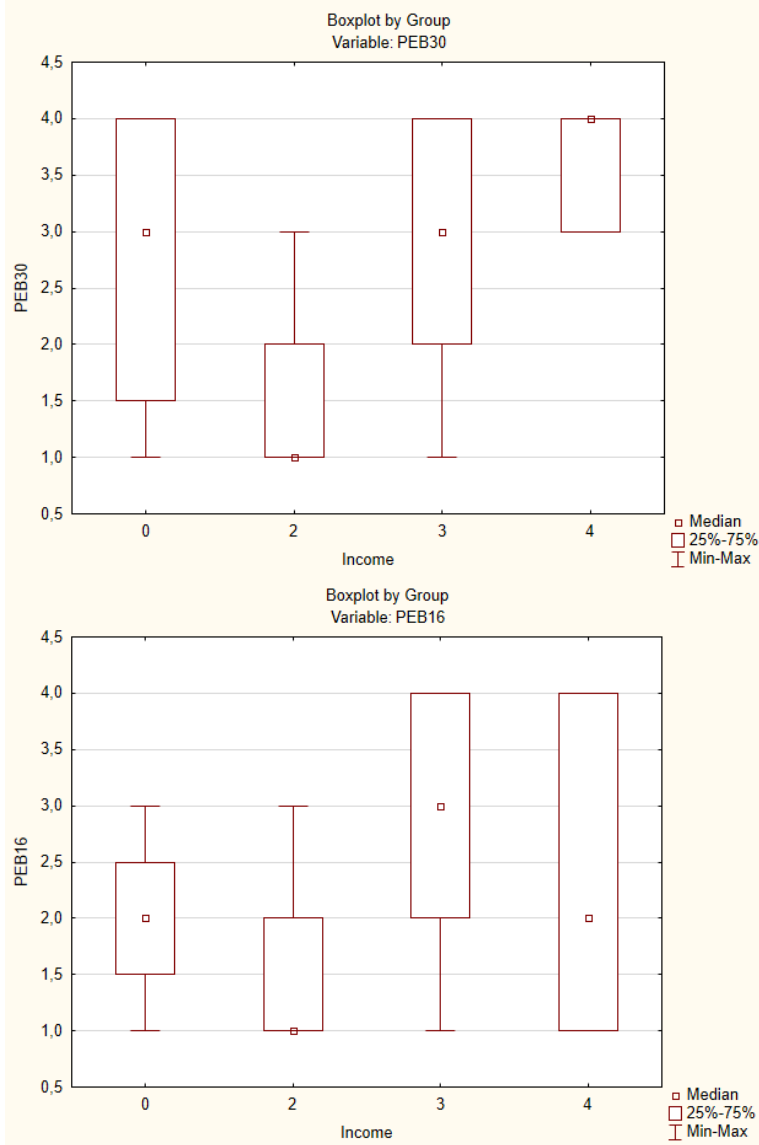

Figure 3 "Box \& Whiskers" Plots for P30 and P16.

Most often, high-income people practice waste separation; low-income people never do this (fig. 4a). And, as the most interesting example, people with a low income never buy processed goods, people with an average income rarely do this, and people with a high income almost never (fig. 4b).

Most likely, the revealed differences are explained not so much by the respondent's income level as by other factors that may be indirectly related to the income level: cultural traditions, living conditions. For a clearer understanding of the impact of income on the frequency of use of a particular model of behavior, additional research is needed.
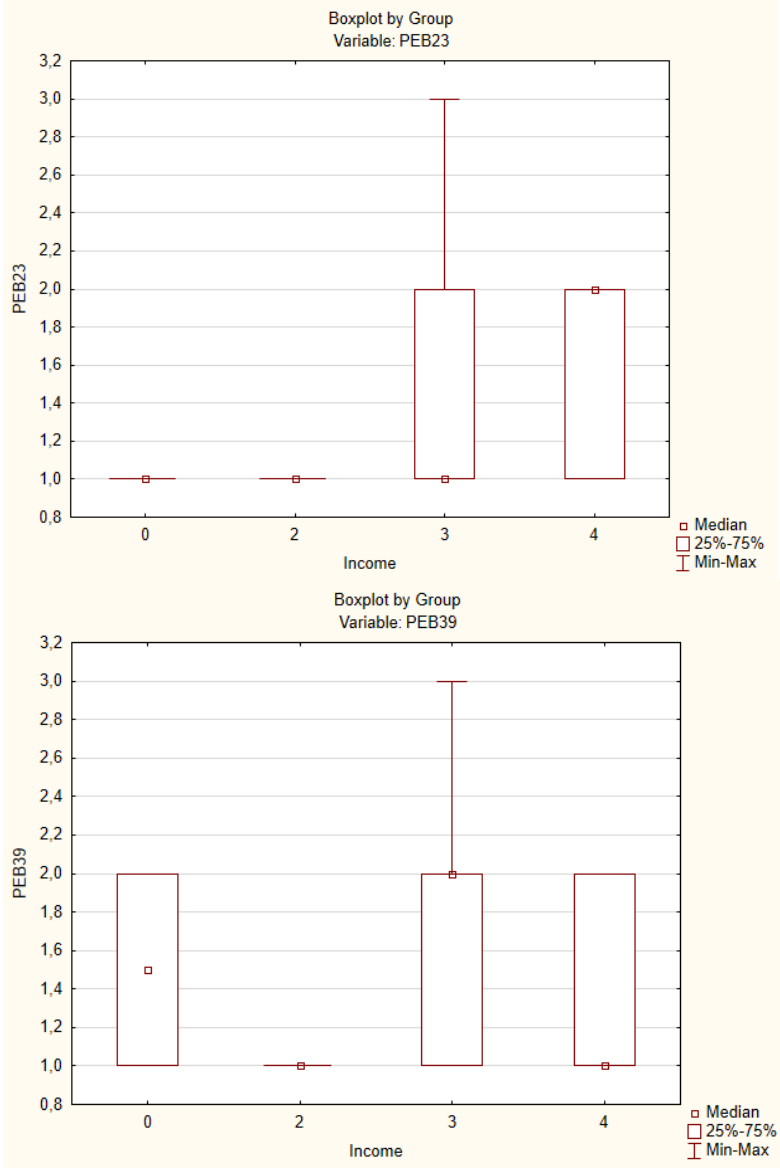

Figure 4 “Box \& Whiskers" Plots for P23 and P39.

\section{CONCLUSION}

The main results of this study are as follows: the most popular among Russian students are energy conservation practices. Their use is not practically related to income and is not the result of an attempt to save. Most likely, the popularity of this group of practices is the result of the promotion of energy conservation, which has been carried out over the past 10 years in the Russian media.

The least popular are waste management practices, which is explained by the underdevelopment of the network of recycling centers, the lack of information among the population about the location and schedule of recycling centers; underdeveloped system of separate collection of garbage, lack of necessary conditions for the implementation of such separate collection; lack of incentives (in addition to a sense of duty) to follow waste management standards and improve the environmental situation.

\section{AUTHORS' CONTRIBUTIONS}

R.S., G.K., developed the theory and performed the computations, verified the analytical methods, contributed to the design and implementation of the research, to the analysis of the results and to the writing of the manuscript. 


\section{ACKNOWLEDGMENTS}

The publication has been prepared with the support of the «RUDN University Program 5-100».

This paper has been supported by the RUDN University Strategic Academic Leadership Program.

\section{REFERENCES}

[1] J. Korhonen, A. Honkasalo, J. Seppälä, Circular Economy: The Concept and its Limitations, Ecological Economics 143 (2018) 37-46.

[2] W. Haas, F. Krausmann, D. Wiedenhofer, M. Heinz, How circular is the global economy? An assessment of material flows, waste production, and recycling in the European Union and the world in 2005, Journal of Industrial Ecology 19 (2015) 765-777.

[3] J. Kirchherr, L. Piscicelli, R. Bour, E. KostenseSmit, J. Muller, A. Huibrechtse-Truijens, \& M. Hekkert, Barriers to the Circular Economy: Evidence From the European Union (EU), Ecological Economics 150 (2018) 264-272. DOI:10.1016/j.ecolecon.2018.04.028

[4] K. Ando, S. Ohnuma, B. Anke, E. Matthies, J. Sugiura, Determinants of Individual and Collective Pro-Environmental Behaviors: Comparing Germany and Japan, Journal of Environmental Information Science 38(5) (2010) 21-32.

[5] K. Ando, S. Ohnuma, E.C. Chang, Comparing Normative Influences as Determinants of Environmentally Conscious Behaviors between the USA and Japan, Asian Journal Of Social Psychology 10(3) (2007) 171-178.

[6] P. W. Schultz, Knowledge, Information, and Household Recycling: Examining the KnowledgeDeficit Model of Behavior Change, New Tools for Environmental Protection: Education, Information, and Voluntary Measures, The National Academic Press (2012) 67-82.

[7] E. Aoki, K. H. Kurisu, J. Nakatani, K. Hanaki, Current State and Interregional Comparison of Citizen's Environmental Behavior by 47 Prefectures, Japan Journal of JSCE 38 (2010) 17-26.

[8] M. Cordano, S. Welcomer, R.F. Scherer, L. Pradenas, V. Parada, A Cross-Cultural Assessment of Three Theories of Pro-Environmental Behavior: A Comparison between Business Students of Chile and the United States, Environment and Behavior 43 (2011) 634-657.

[9] H. Lee, K. Kurisu, K. Hanaki, Influential Factors on Pro-Environmental Behaviors - A Case Study in Tokyo and Seoul, Low Carbon Economy 4 (4)
(2013)

104-116.

DOI:

https://doi.org/10.1016/j.jenvp.2014.09.003.

[10] D. Li, L. Zhao, S. Ma, S. Shao \& L. Zhang, What influences an individual's pro-environmental behavior? A literature review. Resources, Conservation and Recycling 146 (2019) 28-34. DOI: 10.1016/j.resconrec.2019.03.024

[11] S. Phuphisith, K. Kurisu \& K. Hanaki, A comparison of the practices and influential factors of pro-environmental behaviors in three Asian megacities: Bangkok, Tokyo, and Seoul, Journal of Cleaner Production, (2019). DOI:10.1016/j.jclepro.2019.119882

[12] F. Lange \& S. Dewitte, Measuring proenvironmental behavior: Review and recommendations, Journal of Environmental Psychology (2019). DOI:10.1016/j.jenvp.2019.04.009

[13] C. Kormos \& R. Gifford, The validity of self-report measures of proenvironmental behavior. A metaanalytic review, Journal of Environmental Psychology 40 (2019) 359-371.

[14] F. G. Kaiser, M. Merten \& E. Wetzel, How do we know we are measuring environmental attitude? Specific objectivity as the formal validation criterion for measures of latent attributes. Journal of Environmental Psychology 55 (2018) 139-146. DOI: https://doi.org/10.1016/j.jenvp.2018.01.003.

[15] H. Lee, K. Kurisu, K. Hanaki, Influential Factors on Pro-Environmental Behaviors - A Case Study in Tokyo and Seoul. Low Carbon Economy 4(4) (2013) 104-116. DOI: doi.org/10.4236/lce.2013.43011 